University of Nebraska - Lincoln

DigitalCommons@University of Nebraska - Lincoln

To Improve the Academy

Professional and Organizational Development Network in Higher Education

1994

Conducting Cooperative Cases

Barbara J. Millis

Follow this and additional works at: https://digitalcommons.unl.edu/podimproveacad

Part of the Higher Education Administration Commons

Millis, Barbara J., "Conducting Cooperative Cases" (1994). To Improve the Academy. 314.

https://digitalcommons.unl.edu/podimproveacad/314

This Article is brought to you for free and open access by the Professional and Organizational Development Network in Higher Education at DigitalCommons@University of Nebraska - Lincoln. It has been accepted for inclusion in To Improve the Academy by an authorized administrator of DigitalCommons@University of Nebraska - Lincoln. 


\section{Conducting Cooperative Cases}

\section{Barbara J. Millis}

University of Maryland University College

The power of case studies has been well-documented. Most facilitators use the widely known whole-group Harvard discussion model. However, a cooperative case approach serves as an effective alternative or supplementary approach. This article, which uses-appropriately - the example of a cooperative learning case study, provides a detailed look at the cooperative case study method, including its rationale and value, creative group formations, and facilitation guidelines.

\section{Conducting Cooperative Cases}

The case study method is becoming more widely known and used by faculty development workshop presenters and by innovative classroom instructors. Cases bring immediacy and relevance to discussion topics. They also encourage active learning presentation methods by engaging workshop participants or students in stimulating, experiential, real-world scenarios. Such scenarios promote active problemsolving and critical thinking skills. Wilkerson and Boehrer (1992) conclude that cases can be used effectively in workshop settings "to introduce new educational concepts, provoke attitudinal changes, provide practice in solving ... problems, and stimulate the desire to acquire new skills" (p. 253).

Cases too are wonderfully versatile. Faculty developers responsive to the needs of different faculty constituents can, for example, use various versions of case studies. Thus, they may develop chameleon cases, generic classroom-based cases where primary characters can- 
without harm to the content-change their names, genders, and disciplines. For example, Betty Miles, a children's literature instructor in "Betty Miles's Worst Nightmare: A Cooperative Learning Dilemma," easily became Bob Miles, a balding accountant for a five-day cooperative learning workshop sponsored by Deloitte and Touche, one of the big six accounting firms. Later, Betty, renamed Bonnie, slipped quietly to the front of a "Pharmacy, Law and Ethics" classroom during a pharmacy conference. (See Appendices B and C for the opening pages of these cases).

Faculty respond much more readily to a case tailored to their specific interests and needs. They appreciate the use of discipline-specific examples. Often such chameleon cases can be adapted with minimal effort after consultation with colleagues who can provide the urgently needed discipline-specific material and after careful editing to remove inappropriate gender or name references.

Most faculty developers recognize that how material is presented is as important as the material itself. Thus, whenever possible-virtually regardless of the content-faculty developers should themselves use innovative, interactive facilitation strategies with the deliberate aim of encouraging faculty to adopt similar strategies in the classroom. One effective approach-which lends itself beautifully to case studies-is cooperative learning, a highly effective, well-researched classroom pedagogy (Astin, 1993; Cooper, Prescott, Cook, Smith, Mueck, and Cuseo, 1990; Johnson, Johnson, and Smith, 1991). The cooperative learning approach can be applied to virtually any case, but it is particularly well-suited when the content of the case, as in the examples above, is itself cooperative learning.

To illustrate the power of the cooperative case approach, the Betty Miles version of the case (Appendix A) will be used in this article. "Betty Miles's Worst Nightmare" offers an insightful look at a firstday-of-class experience of an instructor well-versed in innovative, cooperative learning techniques. Betty is confident, competent, and well-prepared. But something goes wrong .... Through cooperative learning methods, workshop participants have an opportunity to reflect on Betty's experiences and to offer suggestions for possible corrective and future preventative actions. 


\section{Rationale for a Cooperative Approach}

The most commonly used case discussion format is the wholegroup case method developed by the Harvard Business School (Christensen and Hansen, 1987). This method, used effectively with groups as large as 30 , usually engages all participants in an active, stimulating, teacher-directed discussion. It has the advantage of eliciting multiple viewpoints and drawing on a wide range of experiences. It also results in a shared experience with all participants exposed to the same ideas. The facilitators, too, have ample opportunities to offer summaries, to redirect misunderstandings, and to provide both guidance and a sense of closure.

Sometimes, however, cooperative approaches can offer more effective ways to deliver cases, particularly when, as with "Betty Miles," the content deals with a cooperative classroom setting. Cooperative learning strategies can be used either as a supplement or alternative to the whole-group case method. Thus, with "Betty Miles" form and function will be compatible, and participants will discover in cooperative learning a valuable alternative to the whole-group approach and a proven interactive classroom strategy.

Cooperative learning discussion methods are effective for a number of reasons: (a) the large group-format promotes interactions where usually only one individual at a time is center stage; in cooperative learning teams such as four-person quads, participants experience not this sequential participation, but simultaneous exchanges actively involving one-fourth of the workshop participants at any given moment; (b) whole-group formats-particularly if the exchanges are dynamic and thought-provoking - can sometimes provide risky arenas where less vocal members, sometimes women and minorities, are less likely to speak up, as they would in a small group setting; (c) whole-group exchanges, while intellectually stimulating, may not offer most individuals the opportunity to test their ideas and receive peer feedback within a relatively safe environment; and finally, (d) unlike whole-group discussions, a cooperative learning format where large groups are broken down into smaller units, allows for any number of participants. 
Often the best approach will be a combination of the two models, with both structured small group work and whole-group discussion. The opportunity for whole-group discussion, involving both participant and facilitator input, may be particularly important for the reportouts so that all participants experience the same sense of positive closure. These discussion methods should be explained when the case is introduced.

\section{Introducing the Cooperative Case}

No effective case facilitator ever presumes to wing it: cooperative cases, like others, require extensive up-front planning. Whenever possible, it is helpful to give the case to participants about a week before the workshop. The "Betty Miles" case is short enough, however, that it can be read and digested within seven to ten minutes during the workshop setting. In any event, even if the case is mailed ahead, it is important to give participants a few minutes (three to five) for review. The case pretty much stands alone, so the facilitator need not provide much commentary. If participants are unfamiliar with the case method, then some background information is useful. As with all cooperative learning approaches, procedures and time limits must be clearly defined. Often the first step, however, will be to get participants into structured small groups.

\section{Forming Groups}

Group formation techniques will depend on variables such as the size of the overall group, the relative emphasis on enhancing teaching skills in the workshop setting, and the facilitator's familiarity with cooperative learning techniques.

The facilitator should determine the optimum size of the groups or teams. Three to six participants can work efficiently and effectively. The larger the size of the group, the less opportunity for individual participation. Many cooperative learning practitioners prefer groups of four, often called quads. There are several ways to place participants in their smaller teams. The following four approaches, placed in the order of their complexity, work well for case studies. 
Random Seating: The facilitator can simply ask participants to form groups of a specified size. (Advantage: This is a quick and easy formation method requiring little movement on the part of the participants. Disadvantages: Such teams sometimes are ragged, with more or fewer members; friends sitting together end up on the same team, sometimes resulting in less heterogenous viewpoints.)

Random Count-off: An alternate random group formation method is simply to have participants count off repeatedly up to the number of teams desired. For example, a group of 37 would break logically into nine groups of four members with an extra member added to one team. The participants would simply count off 1-9, 1-9, $1-9,1-9$, and 1 . Then each team unites on the basis of the designated number. (Advantage: Heterogeneity is likely to be achieved. Disadvantages: This formation technique involves movement distasteful to some participants; it will separate people who may prefer to work together; it involves some logistical planning such as placing numbered placards around a room-1, 2, 3-9 in the example-to help teams move quickly into place.)

Structured Problem Solving with Playing Cards: The facilitator distributes playing cards to each participant and at a given point asks them to move into four-person teams on the basis of the card number (aces together, deuces together, etc.) The participants are asked to perform group roles based on the suit of the card (e.g., clubs serve as recorders, diamonds as team discussion leaders, and hearts as reporters). A highly effective technique - one in which classroom use should be emphasized-is to leave the team roles up in the air until just before the discussion begins. Teams thus are given a dual assignment: they must not only discuss the case and reach a consensus or an appropriate summary of discussion points, but they must also be certain that each team member is capable of serving as the team's reporter. Facilitators can point out that this approach in the classroom helps all students attend to the discussion because of their potential whole-class role and encourages group members to coach any teammates who may not be initially prepared to respond. (Advantages: Deliberate heterogeneity is achieved as the cards are distributed, particularly in the classroom; facilitators speak individually to each participant before the workshop officially begins, thus building rap- 
port; the playing cards foster team cohesion and easy role identification; Disadvantages: Same as in Random Count-off.)

Value Line: This fairly complex cooperative learning technique works best with groups of 40 or less simply because of the space requirements. It is effective, however, for achieving balanced team representation on both sides of controversial issues. Facilitators ask participants to decide on their stance on a particular issue such as, with this case study, their acceptance of cooperative learning techniques. Participants assign themselves numbers based on a clearly explained Likert scale (e.g., 5 = strong cooperative learning user and advocate, and 1 = a nonbeliever skeptical about the benefits of structured group work). The participants then line up on the basis of their number. After the lineup is complete-and straightened out, a common problem with large groups in confined spaces - the participants count off from one end of the line to the other. Each person, thus, has a single identification number, ranging from one to the last member's number in the group. The facilitator then forms four-person teams (quads) by determining the center of the line and calling on the two individuals from the ends of the lines and then the two people in the middle. This approach (two extreme ends and two from the center) continues until all participants/students are assigned to teams. (In a class of 20, for example, teams would be composed of the following members: 1,20 , 10,$9 ; 2,19,11,8 ; 3,18,12,7 ; 4,17,13,6 ; 5,16,14,15$.)

Two techniques can facilitate group placement in value lines: (1) facilitators can use a prenumbered transparency, making it easy to strike out the numbers they call and to visualize the progression inward from the ends and outward from the middle; (2) facilitators can ask a workshop participant to write on a board or flip chart the four numbers that compose each team, giving a visual aid to avoid confusion when a large number of people is involved. Playing cards to determine roles can be used effectively with these teams, also. Facilitators can distribute them as the teams are formed by asking one member to come forward to receive them. (Advantages: Value line is effective for case studies that involve polarizing issues by enabling team members to work with people having different opinions, thus providing the disequilibrium necessary to build critical thinking skills; participants are often intrigued by the technique and enjoy seeing the range of opin- 
ions; the physical movement-allowing brief, friendly exchanges with other participants—can be stimulating. Disadvantages: The same as in Random Count-off, but the logistics are even more challenging.)

The group formation method will directly affect the way the case is conducted. The use of playing cards, for example, helps facilitators to quickly assign group roles.

\section{Getting the Groups on Task}

Any cooperative case, like the Betty Miles one, must be sufficiently rich to allow each team to work on at least one focus question. Usually the facilitator will want to begin the case discussion with one or two general questions that can be explored in a whole-group format. All participants, regardless of their group assignment, can voice an opinion, for example, on the questions "What was your first impression of Betty's class?" and "Were the students justified in their opposition to group work?" This warm-up exercise helps sets the tone for open, interactive discussion and builds participant/student camaraderie.

To encourage in-depth discussion,the facilitator should assign each group one (or sometimes two) specific focus questions, rather than expecting each team to cover the wide range of potential topics. If five focus questions (numbers 3-7) remain and there are more than five groups, then two groups can work on the same question. This approach is often desirable because the subsequent report-outs reveal alternate viewpoints and solutions, reinforcing again the value of divergent opinions in a critical thinking setting.

Groups should be given specific instructions and time lines. For example, while introducing the case, the facilitator might also introduce discussion norms, such as listening attentively until each person has finished speaking, asking probing questions, and encouraging all group members to participate. Such instructions might seem fairly commonplace, but stating them up front has the value of empowering group members to challenge-based on the "authority" of the facilitator-any members who are not contributing productively or allowing others to do so. 
The responsibilities of each team member-whether they are general group responsibilities or specific role-related ones such as serving as a leader or reporter-should be clearly delineated. It is important not to overcomplicate group roles by assigning too many or by making the duties overly complex. Adults do not like to feel manipulated. Three roles work well with case studies: (1) leader: keeps the team on task, monitors the time, ensures that all members have an opportunity to participate, and maintains a positive working environment; (2) recorder: summarizes the team's ideas and prepares any materials needed for the final report-out; (3) reporter: presents the team's suggestions/comments/solutions to the assigned focus question(s). In practice, any of these duties can be collapsed, with one or two people playing dual roles.

If the overall group is fairly small and the setting informal, the facilitator can simply suggest appropriate group roles and then allow the team to determine who will fill them. With a larger group (30 or more) and in a more formal workshop setting, much time and confusion is saved if the facilitator simply assigns group roles based on the suits of the card (e.g., hearts serve as leaders, clubs as recorders, and diamonds as reporters).

For a case such as "Betty Miles's Worst Nightmare," 20 to 30 minutes of small-group discussion should be sufficient to allow exploration of the assigned focus questions and preparation for a wholegroup report-out.

As with other cooperative learning tasks, it is always important to assign a sponge or extension activity for groups that work more rapidly than others. Thus, each group must prepare for a report-out on their own question, an activity based either on preassigned roles or on the idea that any of the group members can serve as reporter when called upon. Participants should be told, however, that as time permits, their teams should explore other focus questions, enabling them to relate more directly to the other report-outs. The facilitator should emphasize that this cooperative guideline is particularly important in a classroom setting to insure on-task behavior and to discourage students from rushing through an assignment ("blowing it off," in modern parlance) with the idea that they are then free to do other things. 
Facilitators should make all of these directives crystal clear, often distributing them in writing to each group as well as projecting them on an overhead. For example, the seven focus questions should be given to each participant: If the "Betty Miles" case is mailed ahead, then extra copies of the case and the focus questions should be available at the workshop. When the focus questions are assigned to each newly formed group, the facilitator should reinforce the verbal directives with the visual aid of a transparency marking pen designating the question each team will address (e.g., all teams: Questions 1 and 2; Teams 1 and 6: Question 3; Teams 2 and 7: Question 4, etc.). If the size of the overall group is known beforehand, then these handouts and transparencies can be prepared ahead of time. Less structured group work often falters because participants waste much of their allotted time puzzling over the instructions: "What did she tell us to do?" and/or "Why do we need to talk about another focus questions?" and/or "Does it matter which other one we choose?"

Because case studies often have no right or wrong solutions, closing remarks are particularly important. Facilitators need to monitor their time carefully so that this crucial segment of the workshop is lively, but unhurried. Generally, facilitators should allow about five minutes per report-out and less if the groups are highly focused and well-prepared.

Three procedures work well for closing report-outs. If the overall group is small and informal, then the reporters can simply rise and give an oral summary of the deliberations of their teams. This format has the advantage of following the K.I.S.S. principle, not a bad thing to remember when conducting a cooperative workshop. With larger groups, facilitators can give each team a clean sheet of acetate and a transparency marking pen and encourage the reporters to use visual prompts from the front of the room. Similarly, they can distribute flip chart paper and large markers for the final report-outs. This practice has the advantage of fostering team cohesion, because it usually takes at least two people to hold up the flip chart paper or to tape it to a wall.

If two teams worked on the same focus questions, it is important to encourage two report-outs but to discourage repetition. Another good practice is reversing the order in which groups report. For 
example, teams 1 and 6 can report on Question 3, but teams 7 and 2 (reversing the numerical expectation) can report on Question 4.

It is extremely important for the facilitator to provide official validation in a closing summary, both for the content and the process of the teams' work. The summary need not be long. It is a good practice to repeat, preferably in a congratulatory or even humorous formatavoiding tedious repetition - the advice the teams have given Betty Miles. It is also useful to process the cooperative experience, particularly if one hopes that the participants will translate their case experience at the workshop into active classroom practice. If all has gone well, the teammates will be shaking hands and leaving the workshop session with new knowledge, skills, and friends.

\section{Rethinking the Facilitator's Role}

In a traditional whole-group case study discussion, the facilitator is center-stage, visibly controlling the flow and the content of the discussion. Although good facilitators always encourage participant interactions, often by deliberately asking for responses to specific comments, their presence tends to dominate. Sometimes participants recall, "Wow! What a great discussion that was! What a great case teacher Dr. X is!" Sometimes they forget-unfortunately-the content and specific points of the discussion.

With a cooperative case approach, the facilitator's role is no less important but is often less obvious. The participants play a more direct, interactive role within their structured small groups. They are therefore more likely to remember what transpires, particularly their own contributions. The facilitator essentially plays three critical roles: (1) planner; (2) workshop manager; and (3) group monitor.

Much up-front planning is involved. Facilitators must obviously select the appropriate case, determine-if appropriate-the focus questions, and disseminate material ahead of time when possible. Based on the size of the group and other factors, they must coordinate a facilitation strategy that includes group formation (method, size, and seamless movement); focus question assignments including the format for group report-outs; workshop management techniques; and suitable closure methods. They must also have prepared the workshop 
handouts, overhead transparencies, and any needed supplies, such as blank acetate sheets or flip chart paper and markers.

Before the various groups begin their discussions, as suggested earlier, facilitators must make crystal clear the case guidelines, procedural instructions, and rationale.

Furthermore, depending on the size of the overall group, they may want to establish a quiet signal of some sort to bring teams back to full attention. Often a raised hand works well. Whenever participants see the facilitator's raised hand, they finish their sentence, raise their own hand, and direct their teammates' attention to the quiet signal. Using this technique, an entire room full of participants can come to attention in a matter of seconds. It is usually a good idea to good-naturedly ask participants to practice the raised hand signal before the discussion begins; otherwise, the procedure seems awkward and possibly childish. Some facilitators also augment the raised hand with some sort of auditory signal, though such devices-bells or timers - should be used cautiously. They can annoy some participants.

Probably the facilitator's most important role is monitoring the groups as they discuss the case. They should do so whenever possible by sitting down among the groups, largely as silent observers but prepared to contribute if participants have questions or if the discussion takes a counterproductive turn. This monitoring role pays enormous dividends: (1) it builds good will because the workshop participants feel that the facilitator is genuinely interested in their ideas; (2) it helps the facilitator identify any problem areas in content or process; (3) it allows the facilitator to monitor the teams' progress so that times can be adjusted, if feasible, to allow more or less team discussion; (4) it enables the facilitator to get to know participants in a far more personal way than could ever occur with an intervening podium; and (5) it is far more interesting and rewarding for the facilitators themselves.

\section{Conclusion}

The power of cases, like the power of "stories," is well-known. They bring immediacy and reality to potentially theoretical material. They stimulate in-depth, collaborative problem-solving and thought- 
provoking context-specific discussions. Perhaps best of all, they offer opportunities for active, experiential learning.

Similarly, the power of cooperative learning techniques has been well-documented by both researchers and practitioners. Structured small group work increases achievement, builds harmonious bridges among diverse participants, increases self-esteem by making certain that all contributions are valued, and develops important critical thinking and interpersonal skills vitally needed for today's workplace.

Using cooperative learning techniques to facilitate case discussions results in the best of all possible worlds. When a case like "Betty Miles's Worst Nightmare" deals with the subject of cooperative learning, then it is only natural to model the process as the case unfolds. Thus, participants can leave a cooperative case discussion with both the knowledge and the skills to conduct similar case discussions in their own classrooms.

\section{References}

Astin, A. W. (1993). What matters in college: Four critical years revisited. San Francisco: Jossey-Bass.

Christensen, C. R., \& Hansen, A. J. (1987). Teaching and the case method: Text: cases, and readings. Boston: Harvard Business School.

Cooper, J., Prescott, S., Cook, L., Smith, L., Mueck, \& Cuseo, J. (1990). Cooperative learning and college instruction. Long Beach, CA: The California State University Foundation.

Johnson, D. W., Johnson, R. T., Smith, K. A. (1991). Cooperative learning: Increasing college faculty instructional productivity (ASHE-ERIC Higher Education Report No. 4). Washington, DC: The George Washington University School of Education and Human Development.

Wilkerson, L., \& Boehrer, J. (1992). Using cases about teaching for faculty development. In D. H. Wulff \& J. D. Nyquist (Eds.), To improve the academy: resources for faculty, instructionah and organizational development, 11 (pp. 253-262). The Professional and Organizational Development Network in Higher Education, Sillwater, OK: New Forums Press, Inc. 


\section{APPENDIX A}

\section{BETTY MILES'S WORST NIGHTMARE: A COOPERATIVE LEARNING DILEMMA}

"Hi, I'm Betty Miles," smiled the tall, dark-haired instructor near the door. "Welcome to Modern Children's Literature."

Students clutching Charlotte's Web and other weighty tomes, some glancing nervously at their watches, scurried into the classroom, eying the orderly desks arrayed with thick packets of materials. As the greetings continued, they arranged their book bags, purses, and notebooks, and most of them began thumbing through the 13-page syllabus. After a few minutes, they noticed the course information neatly printed on the board with the instructor's name and the instructions asking them to complete a personal data sheet included with the syllabus material.

At 1:05 p.m. when 24 students were in place, Betty Miles walked to the front of the room and called the class to order.

"Are the brothers Grimm too grim for children?" she asked rhetorically. "Do you want your pre-teen reading Dinky Hocker Shoots Smack? This semester we'll be exploring these and other issues in the far-from-childish world of children's literature. Before we begin our discussions, however, I'd like us to get better acquainted. If you haven't already done so, could you please complete the pink Personal Data Sheet on top of your syllabus while I put the evening's agenda on the board. Also, please be prepared to move to a different seat in five minutes."

Several students looked puzzled, but most dutifully scribbled on their pink sheets. Of the 24 students, all but six were women, ranging in age from fresh-faced teenagers to a grandmotherly-type sitting in the back row. One of the males, a short, soft-featured man in his early 30 s, sported a single gold earring.

"As you can see by the agenda," said Betty, "we will now begin with an icebreaker called the three-step interview. After that, we'll cover the course objectives and requirements, and then we'll begin our exploration of trends and issues in children's literature. We'll con- 
clude promptly at 1:50 p.m. Are there any questions about what we'll do today?"

After waiting expectantly but finding no hands raised, Betty explained the interview process. "I want each of you to identify someone in the room who seems unlike you, someone perhaps of a different gender, age, or race. The person with the shortest hair will begin by asking interview questions of the other partner. I've put four suggested questions on the board. The most important are 'Why are you taking this course? What do you hope to get out of it?' Interview for two minutes. Then, when I ring this little bell" $\rightarrow$ she demonstrated it- "switch roles and have the other person ask the same questions. Then, when you hear the bell again, each pair should find another pair, making a foursome. For the next five minutes, introduce your partners to the group so that you all know each other by the end of the session. Don't try to repeat all you have learned during the pair introduction. Just concentrate on the most interesting points. Are the instructions clear?" Betty looked around. "Okay, begin."

The room filled with milling people suddenly engaged in animated conversations. Betty moved skillfully around the room, making certain that each person had a partner. About halfway through the exercise three students straggled in, but she carefully paired two of them and integrated the third into a circle of four just forming.

As the time expired, Betty rang the bell, but the room was still filled with noise and laughter.

Betty, anticipating this response, now flicked the lights and finally brought the class to attention.

"We need a quiet signal," she announced, "to bring order from anarchy because we'll be working in groups a lot this semester. It could be anything that will bring you to attention, but we need to create a ripple effect. For example, if you choose a raised hand, whenever one of you sees a hand raised, you need to finish your sentence and raise your hand. The room can come to order that way in less than $\mathbf{3 0}$ seconds."

"A raised hand seems too childish," said a tall, blond girl in a checked sundress. "How about flashing the ' $\mathrm{V}$ ' for victory sign?

"That's a good idea," chimed another. 
"Ok, if we're in agreement," said Betty. "We'll make that our signal. Often, I'll use both the victory sign and the bell. Please stay with your new team and let's begin our discussion of the syllabus."

Betty carefully explained all aspects of the course, including the journal assignments, the reading cards due every third class period, the chapter reading quizzes, and the book shares. Students asked few questions, but one studious-looking girl with glasses said, "Wow, this is a lot more work than I expected."

During the discussion, Betty emphasized the importance of teamwork and cooperation. "You will help each other learn," she emphasized. "Next week I'll put you in assigned learning teams where you can coach one another over the chapter material, but each of you will take the quizzes individually. Each of you on a high-achieving team will get a bonus point for each five points the team, as a whole, improves over the last quiz."

Betty glanced at her watch. "This team approach may be new to you. There's time, I think, for me to get your reactions. Let's do an exercise called 'Numbered Heads.' Could you please call out numbers-one-two-three-four-in your current teams so that everyone has a number. Go ahead-anyone can start." Class members glanced uncertainly at one another, but soon cries of "one-two-three-four" reverberated throughout the room.

Betty smiled approvingly. "Good work! I'd like you to take the next seven minutes to talk as a team about your feelings about the course. When you see the quiet signal or hear the bell, I'll ask about three of you to share your responses with the entire group. I will call on you by number to represent not your own opinion, but the team's consensus. You won't know which number I will call, so I hope that all of you will pay attention, summarizing the discussion so that you can present an accurate assessment of the team thinking. Those of you who rarely speak out in classes should feel more comfortable at giving a team response. Okay, begin."

The buzz sessions went smoothly. Betty moved rapidly among the groups, trying to remain as unobtrusive as possible. One group, in fact, was involved in such a heated discussion that they didn't notice her poised confidently in a desk outside the perimeter of their circle. As 
she listened to their remarks, however, Betty's confidence began to evaporate.

The man with the earring had obviously been speaking for several minutes: "I think it sucks," he said. "I'm here to get a good grade. Period. I don't want to have to wade through all this 'hold-me touch-me feel-me' crap. I'm sorry to sound so negative, but I paid good tuition money to get three credits of upper level English out of the way. This looked like an easy course, and I was willing to tolerate a little 'Mary Has a Little Lamb' garbage during lectures, but now I feel like I'm expected to spill my guts on the Phil Donahue show."

A plump, brown-eyed young woman spoke next: "Well, I don't mind cooperating. In fact, I think it's a good idea. In too many of my classes I've felt like a Social Security number. The grade is the problem for me. I heard the teacher say that the cooperative learning grade works like bonus points. It can't hurt us. But frankly, I'm skeptical. What if half you guys-you, for example, John-don't show up or you don't do the work. I'm stuck with freeloaders no matter how hard I work."

"Yeah, that bugs me, too," said another young woman. "In my last class the teacher dumped us in teams, and I did all the work. I wrote the whole group project on my own. The other students seemed to sense that I would do it. I don't know why I did it-the grade I guess - but I also liked our topic on homeless people. I didn't get any help from the teacher, either, and that bothered me even more. He seemed preoccupied with some survey he was conducting on the urban poor."

"The same stuff happened to me," said the woman in the sundress. "Group work, no matter what fancy name you give it, seems a cop out. The teacher doesn't have to do any work. She expects us to share resources and ideas. What if we can only pool our own ignorance? I'm really -uh-nervous about this class."

Betty slipped away to the next team, but her mind stayed focused on the conversation she had just overheard. What should she do? She immediately considered the question of whether or not she should she call on someone from the last team to share their responses? But she wondered, also, if other people in the class were feeling so negative. How could she turn this situation around? 


\section{FOCUS QUESTIONS}

Betty Miles's Worst Nightmare:

A Cooperative Learning Dilemma

1. What was your first impression of Betty's class?

2. Were the students justified in their opposition to group work?

3. Should Betty call on someone from the disgruntled group?

4. What can Betty do during this class session to turn this situation around?

5. What should she do the next class period?

6. What arguments in favor of structured small group work (cooperative learning) might convince dualistic thinkers to "buy into" it?

7. The next time Betty offers this course, what should she do differently? 


\section{APPENDIX B}

\section{BOB MILES'S WORST NIGHTMARE: A COOPERATIVE LEARNING DILEMMA}

\section{Written by Barbara Millis, Assisted by Philip Cottell}

"Hello, I'm Bob Miles," smiled the tall, slightly bald young instructor near the door. "Welcome to Accounting Ethics."

Students, some glancing nervously at their watches, scurried into the classroom, eying the orderly desks arrayed with thick packets of materials. As the greetings continued, they arranged their book bags, purses, and notebooks, and most of them began thumbing through the 13-page syllabus. After a few minutes, they noticed the course information neatly printed on the board with the instructor's name and the instructions asking them to complete a personal data sheet included with the syllabus material.

At 12:05 p.m. when 34 students were in place, Bob Miles walked to the front of the room and called the class to order.

"Pretend you just discovered a huge unfavorable material quality variance during a review of a cost accounting system that your company had implemented for another firm," Bob said. "If you report the variance, your company-which needs the business-stands to lose this firm as a client. You know you can cover up the variance by prorating it among several inventory accounts and cost of goods sold. You know also that your manager would want you to quietly take the latter course of action and might fire you if you 'whistle blow' instead. What would you do? This semester we'll be exploring these and other issues through 'real world' cases in the complex world of high finance."

He nodded cheerfully. "Before we begin our discussions, however, I'd like us to get better acquainted. If you haven't already done so, could you please complete the yellow Personal Data Sheet on top of your syllabus while I put the evening's agenda on the board. Also, please be prepared to move to a different seat in five minutes." 


\section{APPENDIX C}

BONNIE MILES'S WORST NIGHTMARE:

A COOPERATIVE LEARNING DILEMMA

\section{Written by Barbara Millis, Assisted by Carol Weiss, Eric Boyce, Marven Myers, \& Richard Penna}

"Hello, I'm Bonnie Miles," smiled the tall, dark-haired instructor near the door. "Welcome to Pharmacy Law and Ethics."

Students, some glancing nervously at their watches, scurried into the classroom, eying the orderly desks arrayed with thick packets of materials. As the greetings continued, they arranged their backpacks, purses, and notebooks, and most of them began thumbing through the 13-page syllabus. After a few minutes, they noticed the course information neatly printed on the board with the instructor's name and the instructions asking them to complete a personal data sheet included with the syllabus material.

At 12:05 p.m. when 34 students were in place, Bonnie Miles walked to the front of the room and called the class to order.

"Welcome. I want you to pretend you are a pharmacist at a large teaching hospital. You find yourself in the position of dispensing either an experimental drug or a placebo to patients during a clinical trial. The physicians do not know which patients are receiving the placebos, but you do. You notice that those receiving the new drug are improving, but those receiving the placebo are deteriorating. Can you ethically continue to dispense these medications? Imagine now that you are taking a late night shift at a community pharmacy. One of your better-known patients comes in with a prescription you are convinced could cause him ill effects. You telephone the doctor, whom you don't know well, and he is visibly irritated by the interruption after working hours. As you explain your concern, he grows even more angry, telling you that you are presumptuous to question his authority. He finally demands that you either fill the prescription or send the patient elsewhere and hangs up. What do you do? And finally, a woman you know well socially has you fill a prescription for a drug you know is for AIDS. You also know that your best friend is having an affair with 
her. What are your ethical responsibilities, given the need for patient confidentiality? This semester we'll be exploring such 'real world' cases in order to understand and come to grips with the day-to-day responsibilities and ethical issues of pharmacists.

She nodded cheerfully. "Before we begin our discussions, however, I'd like us to get better acquainted. If you haven't already done so, could you please complete the yellow Personal Data Sheet on top of your syllabus while I put the evening's agenda on the board. Also, please be prepared to move to a different seat in five minutes." 